UDC 666.9.035

Author: PANINA Tatyana Ivanovna, Master, Postgraduate Student of the Department «Technique and technology of nanoproducts manufacture», Tambov State Technical University (Russia), Sovetskaya str., 106, Tambov, Russia, 392000, tanchora68@yandex.ru;

Author: TOLCHKOV Jurij Nikolaevich, Master, Postgraduate of the Department «Technique and technology of nanoproducts manufacture», Tambov State Technical University (Russia), Sovetskaya str., 106, Tambov, Russia, 392000, tolschkow@mail.ru;

Author: TKACHEV Aleksej Grigorevich, Doctor of Technical Sciences, Professor, Head of the Department «Engineering nanotechnology», Tambov State Technical University (Russia), Sovetskaya str., 106, Tambov, Russia, 392000, postmaster@kma.tstu.ru;

Author: MIKHALEVA Zoya Alekseevna, Ph.D. in Engineering, Associate Professor of the Department «Engineering nanotechnology», Tambov State Technical University (Russia), Sovetskaya str., 106, Tambov, Russia, 392000, zoyamih3@gmail.com;

Author: GALUNIN Evgenij Valerevich, Ph.D. in Engineering, Senior Researcher of the Department «Technique and technology of nanoproducts manufacture», Tambov State Technical University (Russia), Sovetskaya str., 106, Tambov, Russia, 392000, evgeny.galunin@gmail.com;

Author: MEMETOV Nariman Rustemovich, Ph.D. in Engineering, Associate Professor of the Department «Engineering nanotechnology», Tambov State Technical University (Russia), Sovetskaya str., 106, Tambov, Russia, 392000, nanotam@yandex.ru;

Author: POPOV Andrei Ivanovich, Ph.D. in Pedagogics, Associate Professor of the Department «Technique and technology of nanoproducts manufacture», Tambov State Technical University (Russia), Sovetskaya str., 106, Tambov, Russia, 392000, olimp_popov@mail.ru

\title{
EFFICIENCY OF APPLICATION OF COMPLEX NANOMODIFYING ADDITIVES BASED ON ZEOLITES IN BUILDING MATERIALS
}

\section{Extended Abstract:}

The paper considers the possibility of using integrated multifunctional additives based on carbon nanotubes and zeolites (natural and synthetic) in construction materials. The nanotubes were produced by catalytic chemical vapor deposition. The streamlined modification of the zeolite structure was performed by impregnating initial materials with a nanotubes-supported catalyst. The present experimental research focused on studying the effect of the synthesized nanomodifying additive on the physicomechanical properties of a composite construction material. Based on the obtained data, it was assumed that when entering the concrete structure, zeolite acts not only as mineral additive but also as nanotubes carrier under the chosen nanomodification conditions for the construction ma- 
terial, thereby allowing for uniform distribution of carbon nanoparticles in the composite matrix; on the other hand, the adsorption properties of zeolite can be reinforced by the presence of carbon in the structure. Structures of nanomodifying zeolites and obtained building composite were evaluated by scanning electron microscopy (SEM). Electron micrographs of the objects makes it possible to explain the processes of formation of the concrete structure, nanomodified complex multifunctional additive based on synthetic and natural zeolites and carbon nanomaterial.

Keywords: fine-grained concrete, nanomodifying, synthetic zeolite, natural zeolite, carbon nanotubes, synthesis.

DOI: dx.doi.org/10.15828/2075-8545-2016-8-5-116-132

MACHINE-REAdABLE INFORMATION ON CC-LICENSES (HTML-CODE) IN METADATA OF THE PAPER

$<$ a rel="license" href="http://creativecommons.org/licenses/by/4.0/" ><img alt="Creative Commons License" style="borderwidth:0" src="https://i.creativecommons.org/l/by/4.0/88x31.png" $/></ \mathrm{a}><$ br $/><$ span xmlns:dct="http://purl.org/ dc/terms/" href="http://purl.org/dc/dcmitype/Text" property="dct:title" rel="dct:type" $>$ Efficiency of application of complex nanomodifying additives based on zeolites in building materials $</$ span $>$ by $<$ a xmlns:cc $=$ "http://creativecommons. $\mathrm{org} / \mathrm{ns} \#$ " href="Nanotehnologii v stroitel'stve = Nanotechnologies in Construction. 2016, Vol. 8, no. 5, pp. 116-132. DOI: dx.doi.org/10.15828/2075-8545-2016-8-5-116-132" property="cc:attributionName" rel="cc:attributionURL" $>$ Panina T.I., Tolchkov J. N., Tkachev A.G., Mikhaleva Z.A., Galunin E. V., Memetov N.R., Popov A.I. </a > is licensed under a $<$ a rel="license" href="http://creativecommons.org/licenses/by/4.0/" >Creative Commons Attribution 4.0 International License $</ \mathrm{a}>$. $<$ br $/>$ Based on a work at $<$ a xmlns:dct="http://purl.org/dc/terms/" href="http://nanobuild.ru/en_EN/ nanobuild-5-2016" rel="dct:source" $>$ http://nanobuild.ru/en_EN/nanobuild-5-2016</a $>$. $<$ br $/>$ Permissions beyond the scope of this license may be available at $<\mathrm{a}$ xmlns:cc="http://creativecommons.org/ns\#" href="olimp_popov@mail.ru" rel="cc:morePermissions">olimp_popov@mail.ru</a>.

\section{References:}

1. Korolev A.S., Hakimova E'.Sh. Melkozernistye betony s nanodobavkami sinteticheskogo ceolita [Fine-grained concretes with synthetic zeolite nanoadditives]. Beton i zhelezobeton Concrete and Reinforced Concrete. 2008, pp. 13-15. (In Russian).

2. Burakov A.E., Romancova I.V., Burakova E.A., Tkachev A.G., Tugolukov E.N. Povyshenie kachestvennyh harakteristik adsorbentov pri formirovanii poverhnostnoj struktury uglerodnyh nanotrubok kataliticheskim pirolizom uglevodorodov [Production of qualitative characteristics of adsorbents in formation of surface structure of carbon nanotubes by means of hydrocarbn catalytic pyrolysis]. Sorbcionnye i hromatograficheskie processy [Sorption and chromatographic processes]. 2013, pp. 334-342. (In Russian). 
3. Brek D. Ceolitovye molekulyarnye sita [Zeolite molecular screens]. Moscow, Mir, 1976, pp. 781. (In Russian).

4. Tkachev A.G., Blinov S.V., Memetov N.R. Carbon nanomaterials on the of catalytic hydrocarbon pyrolysis: development and perspective use. NATO Science for Peace and Security Series A: Chemistry and Biology. 2007, pp. 515-519.

5. Banerjee R., Phan A., Knobler C., Keeffe M., Omar M., Yaghi M. (2008) High throughput synthesis of zeolitic imidazolate frameworks and application to $\mathrm{CO}_{2}$ capture: Science. 2008, pp. 939-943.

6. Patent for invention № 2348 588. Suhaya stroitel'naya smes' [Dry construction mixture].

7. Frigione G., Zenone $F$. The effect of chemical composition on Portland cement clinker grindability: Cement and Concrete Research. 1983, pp. 483-492.

8. Ovcharenko G.I., Sviridov V.L, Francen V.B. (1997) The use of natural zeolites in Russia during the cements concretes production: 13 Internationale Baustofftagung. Weimar (BRG). 1997, pp. 366-373.

9. Scott M.Auerbach, Prabir K. Dutta. Zeolite science and technology. Marcel Dekker, Inc. 2003, p. 1204.

10. Pozhidaev D.A., Kozin A.V. Chuguevskie ceolity, kak mineral'naya dobavka v stroitel'nye materialy [Chuguevskie zeolites as the mineral additive for building materials]. Sovremennye tehnologii v stroitel'stve, dizajne, arhitekture [Modern technologies in construction, design, architecture]. 2013, pp. 71-74. (In Russian).

11. Vlasov V.A. The review of patents in the area of nanotechnologies and nanomaterials. Part 1. Nanotehnologii v stroitel'stve = Nanotechnologies in Construction. 2015, Vol. 7, no. 2, pp. 101-114. DOI: dx.doi.org/10.15828/2075-8545-2015-72-101-114.

12. Goryushkin V.V. Bentonitovye gliny yugo-vostoka Voronezhskoj anteklizy [Bentonite clay of Voronezh south-east anteclise] Thesis abstract. Voronezh State University. 2006. (In Russian).

13. Ovcharenko G.I. Ceolit v stroitel'nyh materialah [Zeolite in building materials]. Publishing House AltGTU, 1995. 102 p. (In Russian).

14. Chernyshov E.M. The nanotechnology studies of construction composites: general considerations, main directions and results. Nanotehnologii v stroitel'stve = Nanotechnologies in Construction. 2009. V.1, no. 1, pp. 45-60. (In Russian).

15. Hakimova E'.Sh. Cementnye betony s nanodobavkami sinteticheskogo ceolita [Cement concretes with nanoadditives of synthetic zeolite]. Vestnik YuzhnoUral'skogo gosudarstvennogo universiteta. Seriya: Stroitel'stvo i arhitektura. 2008. № 25 (125), pp. 16-21. (In Russian).

16. Zhdanov S.P. Sinteticheskie ceolity [Synthetic zeolites]. Moscow, Himiya [Chemistry]. 1981, $264 \mathrm{p}$.

17. Smirnov V.A., Korolev E.V., Al'bakasov A.I. Razmernye e'ffekty i topologicheskie osobennosti nanomodificirovannyh kompozitov [Size effects and topological char- 
acteristics of nanomodified composites]. Nanotehnologii $\mathrm{v}$ stroitel'stve $=$ Nanotechnologies in Construction. 2011, V. 3, no. 4, pp. 17-28. (In Russian).

18. Kudryavtsev P.G., Figovsky O.L. Nanocomposite organomineral hybrid materials. Nanotehnologii v stroitel'stve $=$ Nanotechnologies in Construction. 2016, Vol. 8, no. 1, pp. 16-56. DOI: dx.doi.org/10.15828/2075-8545-2016-8-1-16-56.

19. Kudryavtsev P.G., Figovsky O.L. Nanocomposite organomineral hybrid materials. Nanotehnologii v stroitel'stve $=$ Nanotechnologies in Construction. 2016, Vol. 8, no. 2, pp. 20-51. DOI: dx.doi.org/10.15828/2075-8545-2016-8-2-20-51.

20. Kudryavtsev P.G., Figovsky O.L. Nanocomposite organomineral hybrid materials. Nanotehnologii v stroitel'stve $=$ Nanotechnologies in Construction. 2016, Vol. 8, no. 3, pp. 16-49. DOI: dx.doi.org/10.15828/2075-8545-2016-8-3-16-49.

21. Chumak A.G., Derevyanko V.N., Petrunin S.YU., Popov M.YU., Vaganov V.E. Structure and properties of composite material based on gypsum binder and carbon nanotubes. Nanotehnologii v stroitel'stve $=$ Nanotechnologies in Construction. 2013, V. 5, no. 2, pp. 27-37. (In Russian).

22. Korolev E.V. Osnovnye principy prakticheskoj nanotehnologii v stroitel'nom materialovedenii: Nanotehnologii v stroitel'stve $=$ Nanotechnologies in Construction 2009. Vol. 1, no. 1, pp. 66-79. (In Russian).

23. Staroverov V.D. Struktura i svojstva nanomodifshchirovannogo cementnogo kamnya [Structure and prperties of nanomodified cement stone]. Abstract of Ph.D.Thesis. SPBGASU. 2009. (In Russian).

24. Lushnikova A.A., Sokovikova M.A., Pudov I.A., Yakovlev G.I., Pervushin G.N., Korzhenko $A$. Formirovanie struktury i svojstv betonov, modificirovannyh dispersnymi dobavkami [Formation of structure and properties of concretes modified with disperse additives]. Vestnik Yuzhno-Ural'skogo gosudarstvennogo universiteta. Seriya: Stroitel'stvo i arhitektura. 2011. № 16 (233), pp. 30-33. (In Russian).

25. Korolev E.V. Princip realizacii nanotehnologii v stroitel'nom materialovedenii [The principle of nanotechnologies implementation in construction material science] Stroitel'nye materialy [Construction materials]. 2013, № 6, pp. 60-64. (In Russian).

\section{DEAR COLLEAGUES!}

THE REFERENCE TO THIS PAPER HAS THE FOLLOWING CITATION FORMAT:

Panina T.I., Tolchkov J. N., Tkachev A.G., Mikhaleva Z.A., Galunin E. V., Memetov N.R., Popov A.I. Efficiency of application of complex nanomodifying additives based on zeolites in building materials. Nanotehnologii v stroitel'stve = Nanotechnologies in Construction. 2016, Vol. 8, no. 5, pp. 116-132. DOI: dx.doi. org/10.15828/2075-8545-2016-8-5-116-132. (In Russian). 
УДК 666.9.035

Автор: ПАНИНА Татьяна Ивановна, магистр, аспирант кафедры «Техника и технологии производства нанопродуктов», ФГБОУ ВО «Тамбовский государственный технический университет» (Россия), ул. Советская, 106, Тамбов, Россия, 392000, tanchora68@yandex.ru; Автор: ТОЛЧкОВ Юрий Николаевич, магистр, соискатель кафедры «Техника и технологии производства нанопродуктов», ФГБОУ ВО «Тамбовский государственный технический университет» (Россия), ул. Советская, 106, Тамбов, Россия, 392000, tolschkow@mail.ru; Автор: ТКАЧЕВ Алексей Григорьевич, д-р техн. наук, профессор, заведующий кафедрой «Техника и технологии производства нанопродуктов», ФГБОУ ВО «Тамбовский государственный технический университет» (Россия), postmaster@kma.tstu.ru;

Автор: МИХАЛЕВА Зоя Алексеевна, к-т техн. наук, доцент, доцент кафедры «Инжиниринг нанотехнологий», ФГБОУ ВО «Тамбовский государственный технический университет» (Россия), ул. Советская, 106, Тамбов, Россия, 392000, zоуаmih3@gmail.com;

Автор: ГАЛУНИН Евгений Валерьевич, к-т техн.наук, старший научный сотрудник кафедры «Техника и технологии производства нанопродуктов», ФГБОУ ВО «Тамбовский государственный технический университет» (Россия), ул. Советская, 106, Тамбов, Россия, 392000, evgeny.galunin@gmail.com;

Автор: МЕМЕТОВ Нариман Рустемович, к-т техн. наук, доцент, доцент кафедры «Инжиниринг нанотехнологий», ФГБОУ ВО «Тамбовский государственный технический университет» (Россия), ул. Советская, 106, Тамбов, Россия, 392000, nanotam@yandex.ru;

Автор: ПОПОВ Андрей Иванович, к-т пед. наук, доцент, доцент кафедры «Техника и технологии производства нанопродуктов», ФГБОУ ВО «Тамбовский государственный технический университет» (Россия), ул. Советская, 106, Тамбов, Россия, 392000, olimp_popov@mail.ru

\section{ЭФФЕКТИВНОСТЬ ПРИМЕНЕНИЯ КОМПЛЕКСНОЙ НАНОМОДИФИЦИРУЮЩЕЙ ДОБАВКИ НА ОСНОВЕ ЦЕОЛИТОВ В СТРОИТЕЛЬНЫХ МАТЕРИАЛАХ}

АННОТАЦИЯ К СТАТЬЕ (АВТОРСКОЕ РЕЗЮМЕ, РЕФЕРАТ):

В данной статье описывается возможность использования комплексных полифункциональных добавок строительного назначения на основе углеродных нанотрубок и цеолитов (синтетических и природных). Синтез УНТ проводили методом каталитического пиролиза CVD. Направленный синтез в структуре цеолита осуществлялся за счет пропитки исходных веществ раствором прекурсоров на основе катализатора синтеза УНТ. Экспериментальные исследования были направлены на изучение влияния наномодифицирующей добавки на физико-механические характеристики строительного композита. Полученные данные позволили выдвинуть предположение, что при выбран- 
ных условиях модифицирования строительного материала, цеолит, попадая в структуру бетона, будет выполнять роль не только минеральной добавки, но и материала-носителя УНТ, что позволит равномерно распределить углеродные наночастицы в матрице строительного композита, с другой стороны адсорбционные свойства цеолита будут усилены за счет наличия в структуре углеродных элементов. Структуры наномодифицирующих цеолитов и полученного строительного композита оценивались методом электронной сканирующей микроскопии (СЭМ). Электронные микрофотографии исследуемых объектов позволили объяснить процессы формирования структуры бетона, наномодифицированного комплексной полифункциональной добавкой на основе синтетического и природного цеолита и углеродного наноматериала.

Ключевые слова: мелкозернистый бетон, наномодифицирование, синтетический цеолит, природный цеолит, углеродные нанотрубки, синтез.

DOI: dx.doi.org/10.15828/2075-8545-2016-8-5-116-132

МАШИНОЧИТАЕМАЯ ИНФОРМАЦИЯ О СС-ЛИЦЕНЗИИ В МЕТАДАННЫХ СТАТЬИ (HTML-КОД):

< a rel="license" href="http://creativecommons.org/licenses/by/4.0/"><img alt="Лицензия Creative Commons" style="border-width:0" src="https://i.creativecommons.org/l/by/4.0/88x31.png" $/></$ a $><$ br $/>$ Произведение "<span xmlns:dct="http://purl.org/dc/terms/" href="http://purl.org/dc/dcmitype/Text" property="dct:title" rel="dct:type"> Эффективность применения комплексной наномодифицирующей добавки на основе цеолитов в строительных материалах </span>» созданное автором по имени <a xmlns:cc="http://creativecommons.org/ns\#" href="Нанотехнологии в строительстве. - 2016. - Том 8, № 5. - C. 116-132. - DOI: dx.doi. org/10.15828/2075-85452016-8-5-116-132." property="cc:attributionName" rel="cc:attributionURL">Панина Т.И., Толчков Ю.Н., Ткачев А.Г., Михалева 3.А., Галунин Е.В., Меметов Н.Р., Попов А.И. </a>, публикуется на условиях <a rel="license" href="http:// creativecommons.org/licenses/by/4.0/">лицензии Creative Commons «Attribution» ( Атрибуция») 4.0 Всемирная</ a $>$. $<$ br />Основано на произведении с < a xmlns:dct="http://purl.org/dc/terms/" href="http://nanobuild.ru/ru_RU/ nanobuild-5-2016/" rel="dct:source"> http://nanobuild.ru/ru_RU/nanobuild-5-2016/</a $>$. $<$ br />Pазрешения, выходящие за рамки данной лицензии, могут быть доступны на странице <a xmlns:cc="http://creativecommons.org/ns\#" href="olimp popov@mail.ru"rel="cc:morePermissions">olimp_popov@mail.ru</a>.

\section{Введение}

Развитие строительного материаловедения требует тесного взаимодействия с различными отраслями научной и производственной деятельности. Результатом этого взаимодействия является использование прикладных разработок, которое позволит получать композитные материалы с заданными характеристиками и высокими эксплуатационными свойствами $[11,14,18-20,22,25]$. Коммерческой реализацией 
представленного взаимодействия должен быть продукт, отличающийся простотой использования и экономически оправданной стоимостью. Один из самых важных на сегодняшний день операционных переходов в технологии цементных композитов - это направленное использование процессов модифицирования цементного камня с помощью введения нанодобавок [1-7]. Потенциальным фактором решения проблемы модифицирования может быть применение нанотехнологий, перспективность которых заключается в использовании, в том числе, углеродных наноматериалов (УНМ), в качестве дополнительных компонентов системы, способствующих формированию структуры материала с заданными характеристиками.

Анализ текущей ситуации на рынке добавок строительных материалов показал перспективность использования наномодификаторов на основе УНМ [4]. Интерес к данным объектам вызван благодаря их высоким эксплуатационным свойствам, таким как исключительная прочность на растяжение, высокий модуль упругости и ряд других важных показателей. Специфика использования наномодифицирующих добавок заключается в сложности равномерного распределения наноматериала в матрице строительного композита [17]. Успешное решение поставленной задачи откроет новые возможности для создания наноструктурированных строительных композитов с улучшенными функциональными характеристиками.

Благодаря своим ионообменным, адсорбционным и каталитическим свойствам цеолиты находят всё большую сферу применения и являются относительно доступным сырьём по сравнению с другими добавками в строительные композиты. Общим для всех этих минералов является наличие в их структуре трёхмерного алюмокремнекислородного каркаса, образующего систему полостей и каналов. Именно эта специфическая структура обеспечивает уникальность свойств цеолитов.

Выбор цеолита в качестве добавки в строительные композиты обусловлен рядом факторов: высокая поверхностная энергия, химическая активность. С одной стороны, в цеолитсодержащей породе повышено содержание щелочных оксидов, которые ускоряют процессы гидратации комплексного вяжущего, с другой стороны, активный глинозем цеолита связывает сульфат-ионы и выделяющуюся при гидратации клинкерных минералов известь в гидросульфоалюминаты кальция. Причем 
формирование их происходит не на зернах цементного клинкера, а на частицах цеолита или в поровом пространстве. Высвобождение кремнезема из разлагающейся решетки цеолита облегчается, как за счет связывания глинозема из чередующегося алюмокремнекислородного каркаса, так и за счет атаки связей $\mathrm{Si}-\mathrm{O}-\mathrm{Si}$ ионами $\mathrm{Ca}^{2+}$ не только с поверхности образовавшейся «кремнекислородной губки», но и через пористую систему цеолитовых каналов $[5,6,10]$.

Структура цеолита представляет системы каркасов тетраэдров, внутреннее пространство материала содержит полости и каналы, в которых присутствуют молекулы воды и положительные ионы, главным образом $\mathrm{Ca}, \mathrm{Na}, \mathrm{K}$. Размеры каналов у некоторых цеолитов достаточно велики, чтобы в них проникали небольшие органические молекулы и катионы. Лишенный воды цеолит представляет собой микропористую кристаллическую «губку», объем пор в которой составляет до $50 \%$ объема каркаса цеолита $[3,6,13,15-16]$.

Модифицированный цеолит преемственно будет обладать исходными свойствами изначального материала, но присутствие в структуре цеолита углеродного материала будет способствовать более интенсивному взаимодействию с продуктами гидратации цемента, обеспечивая агрегативную устойчивость и прочность межпоровых перегородок композита. Этот факт обусловлен наличием в структуре цеолита свободных молекул и широких пор, в структуру которых возможно включение дополнительных элементов (УНТ) за счет химического взаимодействия.

При правильно выбранных условиях модифицирования в строительном композите формируется структура с заданными параметрами. Кроме того, цеолит, попадая в структуру бетона, будет выполнять роль не только минеральной добавки, но и материала-носителя УНТ, что позволит равномерно распределить углеродные наночастицы в матрице строительного композита, с другой стороны адсорбционные свойства цеолита будут усилены за счет наличия в структуре углеродных элементов.

В представленной работе предложен вариант применения синтетических и природных цеолитов в качестве модификатора строительного назначения, в структуре которого синтезированы углеродные нанотрубки. 


\section{Экспериментальные исследования}

Модифицирование строительных материалов природным и синтетическим цеолитами с синтезированными УНТ проводилось на образцах мелкозернистого бетона. Объектом экспериментальных исследований является добавка на основе синтетического и природного цеолита. Синтетический цеолит представляет собой гранулированные цилиндрические формы длиной 5-8 мм и диаметром $2,9 \pm 0,3$ мм, цвет гранул - серый (рис. 1) [8, 9]. Синтетический цеолит соответствовал формуле СaX, поставляемый ИПГ «Аква-Венчур», г. Санкт-Петербург. Синтетические цеолиты имеют каркасное строение с размером пор 8 ангстрем, что определяет их уникальные свойства $[8,9]$. Природные цеолиты представляют собой бентонитовые глины темно-серого цвета, добываемые на юге-востоке Воронежской антеклизы, по физико-механическим, химико-минералогическим показателям, гранулометрическому составу соответствующие ГОСТ 28177-89 [12]. По дисперсности цеолиты близки к дисперсности цемента (100-120 мкм) (рис. 2).

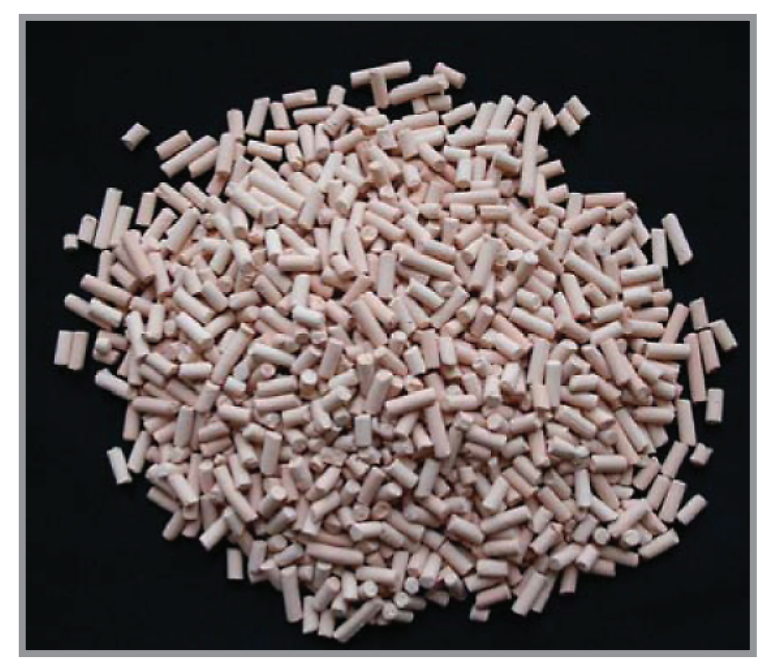

Рис. 1. Синтетический цеолит

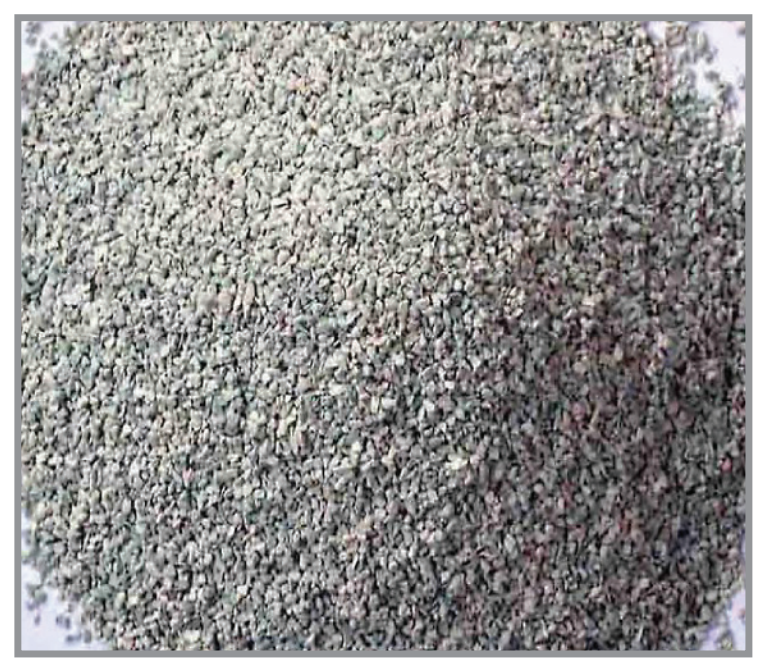

Рис. 2. Природный цеолит

В основе технологии получения наномодифицированных цеолитов лежит метод каталитического пиролиза углеводородов. Процесс синтеза проходит по известной схеме получения углеродных наноматериалов методом газофазного химического осаждения $[2,4]$. 
Процесс синтеза углеродных нанотрубок в поровом пространстве цеолита можно разделить на следующие стадии:

- приготовление и активация исходного раствора гетерогенной металлоксидной каталитической системы (основные компоненты: $\mathrm{Ni}$, $\mathrm{Co}, \mathrm{Y}, \mathrm{Mo}, \mathrm{Mg}, \mathrm{Al}$ );

- предварительная обработка цеолита (механическая, химическая и т.д.);

- пропитка цеолита исходным раствором веществ-прекурсоров катализатора синтеза УНТ;

- термическая обработка пропитанного образца на воздухе при температуре $160 \ldots 220^{\circ} \mathrm{C}$;

- процесс газофазного химического осаждения УНТ на подготовленном образце в промышленном реакторе $\left(\mathrm{t}_{\mathrm{mp}}=650^{\circ} \mathrm{C}\right)$;

- финишная обработка полученного материала (механическое и химическое удаление примесей и агломератов УНТ, незафиксированных в структуре цеолита).

В результате синтеза под воздействием высокой температуры наномодифицированные синтетические и природные цеолиты спекаются, образуя агломераты размером 10-15 мм. В целях обеспечения равномерного распределения добавки в составе смеси компонентов микрозернистого бетона агломераты цеолитов предварительно измельчали в аппарате вихревого слоя $\mathrm{ABC}$ в течение 1 минуты, в результате чего получали мелкодисперсную фракцию (до 50 мкм).

\section{Результаты и обсуждение}

Структура синтетического цеолита, в поровом пространстве которого синтезированы углеродные нанотрубки, представлена на рис. 3. На СЭМ-изображениях наномодифицированных цеолитов видно, что сформированная структура УНТ равномерно покрывает гранулы материала-носителя. Диаметр УНТ составляет 15-25 нм, определяются единичные кристаллы катализатора. Слой углеродного наноматериала не содержит аморфного углерода [2].

Помимо наномодифицирующей добавки в бетонное тесто вводили стандартные синтетические и природные цеолиты. Результаты экспериментов показаны на рис. 4, 5 . 

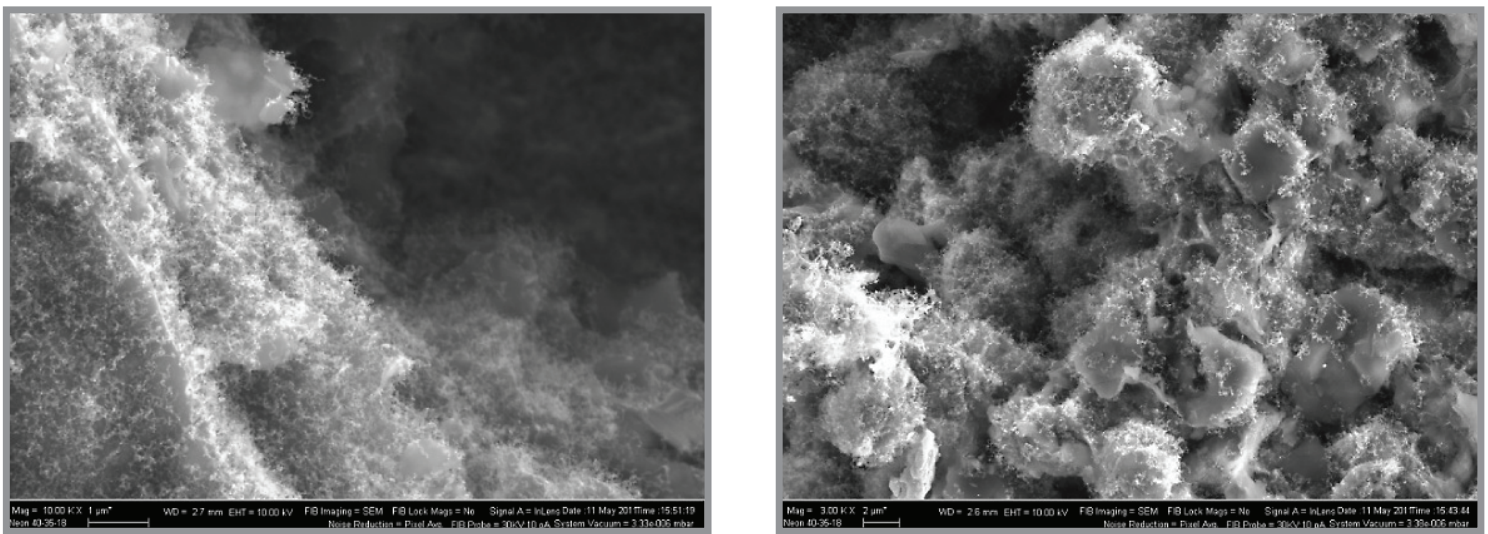

Рис. 3. Электронная микроскопия синтетического цеолита с синтезированными УНТ

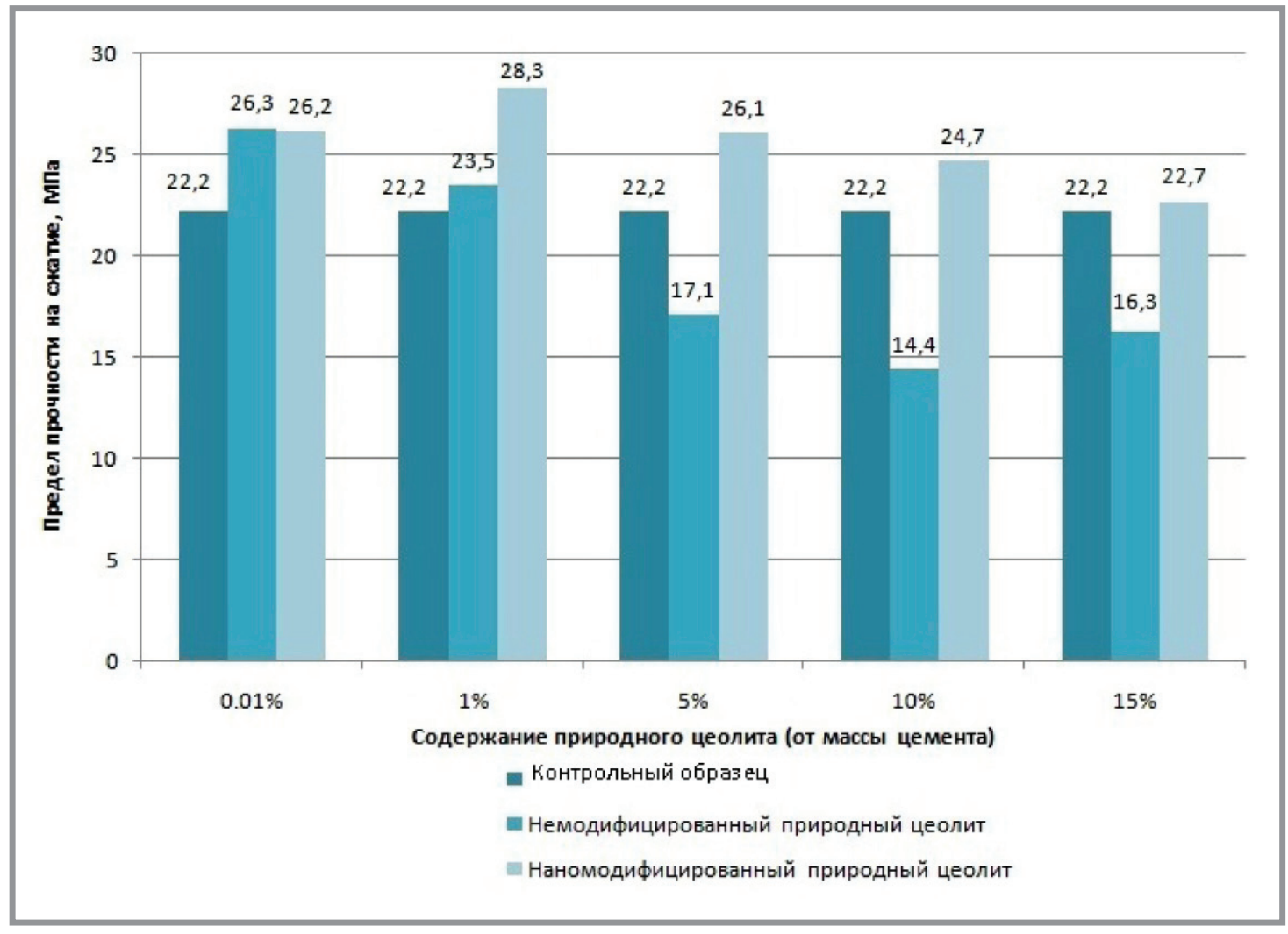

Рuc. 4. Влияние наномодифицированного и немодифицированного природного цеолита на прочностные характеристики бетона 


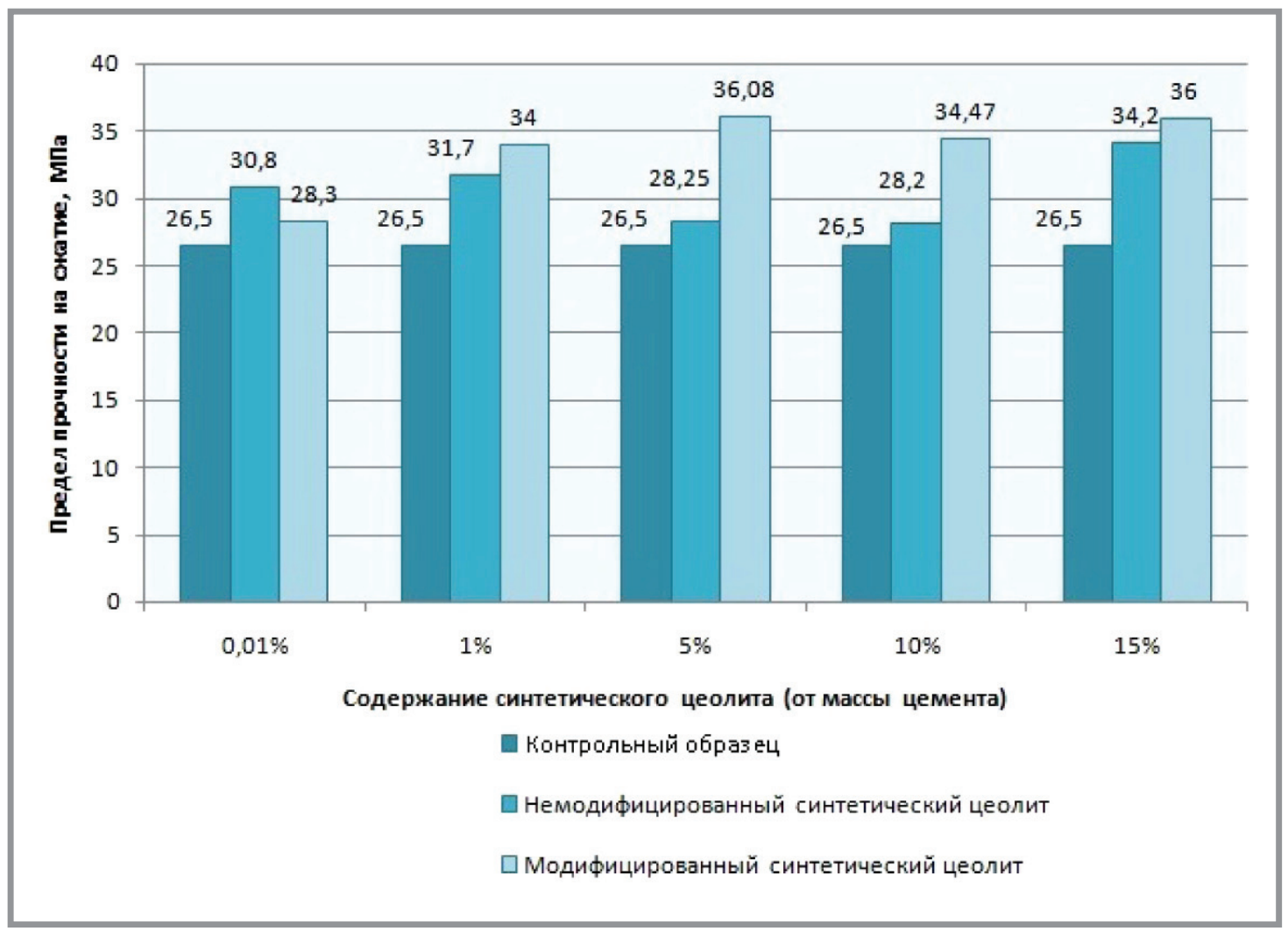

Puc. 5. Влияние наномодифицированного и немодифицированного синтетического цеолита на прочностные характеристики бетона

Анализ экспериментальных исследований (результаты приведены в табл.) показал, что наибольший эффект наблюдается при использовании в мелкозернистых бетонах комплексной добавки в виде наномодифицированного синтетического цеолита. При концентрации наномодифицирующей комплексной добавки 5\% и 10\% от массы цемента прочность на сжатие повышается на $30 \%$.

Структура наномодифицированного цементного бетона отличается наличием новообразований с измененной морфологией кристаллогидратов (рис. 6). Нанотрубки, покрытые гидросиликатами кальция, образуют оболочку, которая плотно соединяет поверхности частиц цемента и наполнителя, делая структуру бетона более прочной. Кроме того, в структуре вышеупомянутого бетона присутствуют низкоосновные гидросиликаты кальция и цеолитоподобные новообразования - анальцим (рис. 6).

Введение цеолитовой добавки в структуру бетона дает возможность поглощать свободные щелочи и анионы, формируя на их основе неор- 


\section{Прочностные характеристики композитов,} модифицированных цеолитами

\begin{tabular}{|c|c|c|c|c|c|c|c|c|c|c|}
\hline \multirow{2}{*}{\begin{tabular}{c}
\multicolumn{1}{c}{ Наименование } \\
Содержание добавки \\
в \% от массы цемента
\end{tabular}} & \multicolumn{5}{|c|}{ Прочность на сжатие, МПа } & \multicolumn{5}{|c|}{$\begin{array}{c}\text { Эффективность \% } \\
\text { относительно контрольного } \\
\text { состава }\end{array}$} \\
\hline & 0,01 & 1 & 5 & 10 & 15 & 0,01 & 1 & 5 & 10 & 15 \\
\hline Синтетический цеолит & 30,8 & 31,7 & 28,5 & 28,2 & 34,2 & 16,2 & 20 & 7 & 7 & 29 \\
\hline $\begin{array}{l}\text { Синтетический цеолит } \\
\text { с УНТ }\end{array}$ & 28,3 & 34 & 36,08 & 34,47 & 36 & 7 & 28,3 & 36,2 & 30,2 & 36 \\
\hline Природный цеолит & 26,3 & 23,5 & 17,1 & 14,4 & 16,3 & 18,4 & 15,5 & 0 & 0 & 0 \\
\hline $\begin{array}{l}\text { Природный цеолит } \\
\text { с УНТ }\end{array}$ & 26,2 & 28,3 & 26,1 & 24,7 & 22,7 & 18,4 & 27,2 & 17,2 & 11 & 2 \\
\hline
\end{tabular}

ганические комплексы. Углеродные нанотрубки, попадая в матрицу бетона, служат центрами кристаллизации и ускоряют процесс роста кристаллов низкоосновных гидросиликатов кальция. Образованные игловидные кристаллы распространяются по всему объему цементного камня равномерно распределенной сеткой, которая плотно соединяет поверхности частиц цемента и наполнителя. В результате поровая
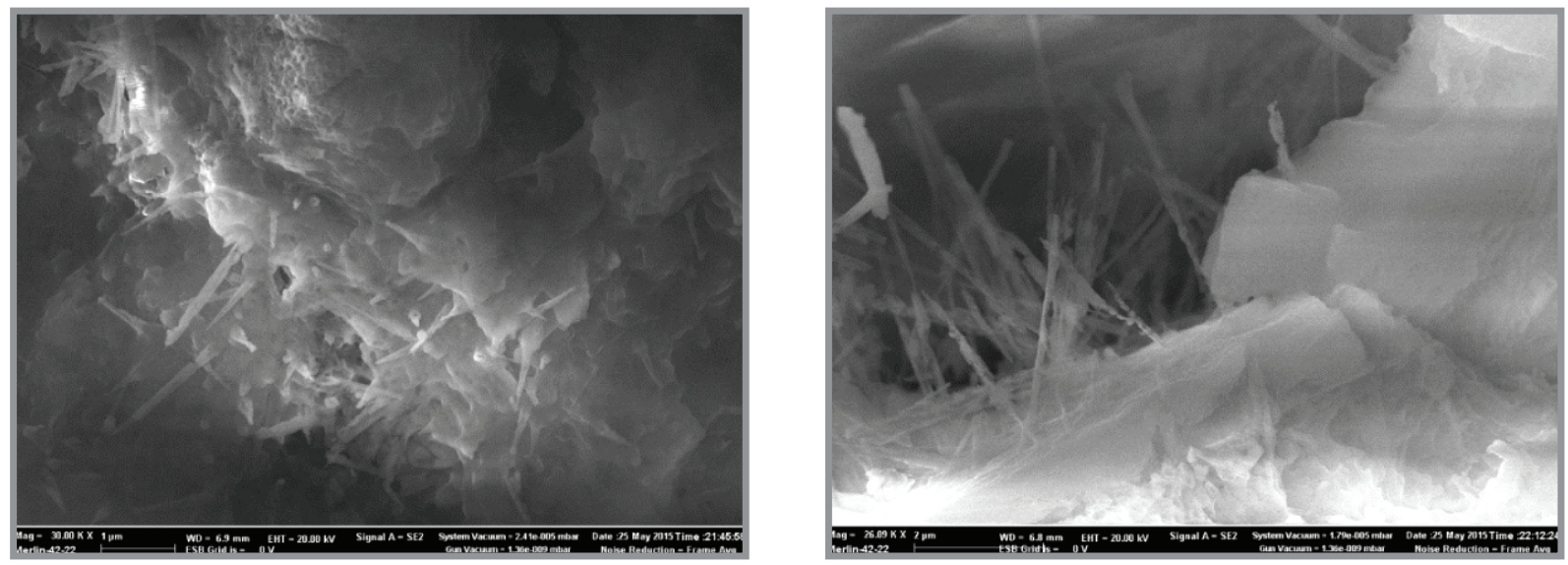

Puc. 6. Электронная микроскопия наномодифицированного мелкозернистого бетона 
структура наномодифицированного камня претерпевает изменения: увеличивается объем микропор с одновременным уменьшением макропор, что способствует образованию более плотной однородной структуры цементного камня [21, 23-24]. Применение наномодифицирующей комплексной добавки позволит существенно снизить расход связующего и наполнителя без снижения марки бетона.

\section{Заключение}

Разработана наномодифицирующая добавка в строительные композиты на основе синтетического и природного цеолита с синтезированными углеродными нанотрубками. Отличительной особенностью полученной добавки является использование цеолита в качестве материала-носителя углеродного наноматериала, обеспечивающей равномерное распределение УНТ в матрице композита.

Анализ результатов по прочностным характеристикам мелкозернистого бетона показал: оптимальное содержание синтетического цеолита с синтезированными УНТ составляет 5\% от массы цемента; оптимальное содержание природного цеолита с синтезированными УНТ составляет 1\% от массы цемента. Установлено, что выявленные концентрации повышают физико-механические характеристики строительного композита на $30 \%$.

Введение полученной добавки в структуру строительного композита способствует изменению порового пространства: увеличивается объем микропор с одновременным уменьшением макропор, что способствует образованию более плотной однородной структуры цементного камня.

Строительные материалы, наномодифицированные добавкой на основе цеолитов с синтезированными УНТ, отличаются более высокими эксплуатационными характеристиками.

Работа выполнена в рамках поддержки кооперащии российских высших учебных заведений, государственных научных учреждений и организаций, реализующих комплексные проекты по созданию высокотехнологичного производства (Постановление Правительства Российской Федеращии от 9 апреля 2010 г. № 218 (Әоговор 02.G25.31.0123 от 14 августа 2014 года). 


\section{УВАЖАЕМЫЕ КОЛЛЕГИ!}

ПРИ ИСПОЛЬЗОВАНИИ МАТЕРИАЛА ДАННОЙ СТАТЬИ

ПРОСИМ ДЕЛАТЬ БИБЛИОГРАФИЧЕСКУЮ ССЫЛКУ НА НЕЁ:

Панина Т.И., Толчков Ю.Н., Ткачев А.Г., Михалева З.А., Галунин Е.В., Мелетов H.P., Попов А.И. Эффективность применения комплексной наномодифицирующей добавки на основе цеолитов в строительных материалах // Нанотехнологии в строительстве. - 2016. - Том 8, № 5. - C. 116-132. - DOI: dx.doi. org/10.15828/2075-8545-2016-8-5-116-132.

\section{DeAR COLleagues!}

THE REFERENCE TO THIS PAPER HAS THE FOLLOWING CITATION FORMAT:

Panina T.I., Tolchkov J. N., Tkachev A.G., Mikhaleva Z.A., Galunin E. V., Memetov N.R., Popov A.I. Efficiency of application of complex nanomodifying additives based on zeolites in building materials. Nanotehnologii v stroitel'stve = Nanotechnologies in Construction. 2016, Vol. 8, no. 5, pp. 116-132. DOI: dx.doi. org/10.15828/2075-8545-2016-8-5-116-132. (In Russian).

\section{Библиографический список:}

1. Королев А.С., Хакилова Э.Ш. Мелкозернистые бетоны с нанодобавками синтетического цеолита: Бетон и железобетон. - 2008. - С. 13-15.

2. Бураков А.Е., Роланцова И.В., Буракова Е.А., Ткачев А.Г., Туголуков Е.Н. Повышение качественных характеристик адсорбентов при формировании поверхностной структуры углеродных нанотрубок каталитическим пиролизом углеводородов: Сорбционные и хроматографические процессы. - 2013. C. 334-342.

3. Брек Д. Цеолитовые молекулярные сита. - М.: Мир, 1976. - С. 781.

4. Tkachev A.G., Blinov S.V., Memetov N.R. Carbon nanomaterials on the of catalytic hydrocarbon pyrolysis: development and perspective use. NATO Science for Peace and Security Series A: Chemistry and Biology. 2007. P. 515-519.

5. Banerjee R., Phan A., Knobler C., Keeffe M., Omar M., Yaghi M. High - throughput synthesis of zeolitic imidazolate frameworks and application to $\mathrm{CO}_{2}$ capture: Science. 2008. P. 939-943.

6. Патент РФ № 2348 588. Сухая строительная смесь. 
7. Frigione G., Zenone $F$. The effect of chemical composition on Portland cement clinker grindability: Cement and Concrete Research. 1983. P. 483-492.

8. Ovcharenko G.I., Sviridov V.L, Francen V.B. The use of natural zeolites in Russia during the cements concretes production: 13 Internationale Baustofftagung. Weimar (BRG). 1997. P. 366-373.

9. Scott M.Auerbach, Prabir K. Dutta. Zeolite science and technology. Marcel Dekker, Inc. 2003. P. 1204.

10. Пожидаев Д.А., Козин А.В. Чугуевские цеолиты, как минеральная добавка в строительные материалы // Современные технологии в строительстве, дизайне, архитектуре. - 2013. - С. 71-74.

11. Власов B.A. Обзор изобретений в области нанотехнологий и наноматериалов. Часть 1 // Нанотехнологии в строительстве. - 2015. - Том 7, № 2. - С. 101114. - DOI: dx.doi.org/10.15828/2075-8545-2015-7-2-101-114.

12. Горюшкин В.В. Бентонитовые глины юго-востока Воронежской антеклизы: автореф. дис. канд. геолог-мин. наук. - Воронежский гос. университет. - 2006. C. 24.

13. Овчаренко Г.И. Цеолит в строительных материалах. - Изд-во: АлтГТУ, 1995. $102 \mathrm{c}$.

14. Чернышов E.M. Нанотехнологические исследования строительных композитов: общие суждения, основные направления и результаты // Нанотехнологии в строительстве. 2009. - Т. 1, № 1. - С. 45-60.

15. Хакилова Э.Ш. Цементные бетоны с нанодобавками синтетического цеолита // Вестник Южно-Уральского государственного университета. Серия: Строительство и архитектура. - 2008. - № 25 (125). - С. 16-21.

16. Жәанов С.П. Синтетические цеолиты. - М.: Химия, 1981. - С. 264.

17. Слирнов B.A., Королев Е.В., Альбакасов А.И. Размерные эффекты и топологические особенности наномодифицированных композитов // Нанотехнологии в строительстве. - 2011. - Т. 3, № 4. - С. 17-28.

18. Кудрявиев П.Г., Фиговский О.Л. Нанокомпозитные органоминеральные гибридные материалы. Часть 1 // Нанотехнологии в строительстве. - 2016. Tом 8, № 1. - C. 16-56. - DOI: dx.doi.org/10.15828/2075-8545-2016-8-1-16-56.

19. Кудрявиев П.Г., Фиговский О.Л. Нанокомпозитные органоминеральные гибридные материалы. Часть 2 // Нанотехнологии в строительстве. - 2016. Tом 8, № 2. - C. 20-51. - DOI: dx.doi.org/10.15828/2075-8545-2016-8-2-20-51.

20. Кудрявиев П.Г., Фиговский О.Л. Нанокомпозитные органоминеральные гибридные материалы. Часть 3 // Нанотехнологии в строительстве. - 2016. Tом 8, № 3. - C. 16-49. - DOI: dx.doi.org/10.15828/2075-8545-2016-8-3-16-49. 
21. Чулак А.Г., Деревянко В.Н., Петрунин С.Ю., Попов М.Ю., Ваганов В.Е. Структура и свойства композиционного материала на основе гипсового вяжущего и углеродных нанотрубок // Нанотехнологии в строительстве. - 2013. - Т. 5, № 2. - С. 27-37.

22. Королев E.B. Основные принципы практической нанотехнологии в строительном материаловедении // Нанотехнологии в строительстве. - 2009. - Т. 1, № $1 .-$ С. 66-79.

23. Староверов В.Д. Структура и свойства наномодифицированного цементного камня: автореф. дис. канд. техн. наук. - СПБГАСУ, 2009. - С. 19.

24. Лушникова А.А., Соковикова М.А., Пудов И.А., Яковлев Г.И., Первушин Г.Н., Корженко А. Формирование структуры и свойств бетонов, модифицированных дисперсными добавками // Вестник Южно-Уральского государственного университета. Серия: Строительство и архитектура. - 2011. - № 16 (233). C. 30-33.

25. Королев E.B. Принцип реализации нанотехнологии в строительном материаловедении / Строительные материалы. - 2013. - № 6. - С. 60-64. 